\title{
Burnout level and associated factors in a sub-Saharan African medical setting: prospective cross-sectional survey
}

\author{
Jean-Rodolphe Mackanga ${ }^{1,2^{*}}$, Emeline Gracia Mouendou Mouloungui ${ }^{2}$, Josaphat Iba-ba², Pierre Pottier ${ }^{3}$,
} Jean-Baptiste Moussavou Kombila ${ }^{2}$ and Jean-Bruno Boguikouma ${ }^{2}$

\begin{abstract}
Background: Burnout in the hospital environment is a problem that affects care and training. Often explored in the high-income medical context, burnout is poorly studied in low and middle-income countries characterized by a precarious hospital situation and a high stake linked to the Millennium Development Goals. The aim of our study was to determine in medical practitioners, in a sub-Saharan African country's medical context, the burnout level and associated factors.

Methods: A prospective cross-sectional study by using a self-administered Likert-scale questionnaire addressed to doctors and doctoral medical students in Gabon. Maslach Burnout Inventory scale has been used. Burnout symptoms were defined by high level in at least one of the 3 dimensions. Severe burnout defined by high level in all dimensions. Explored factors: socio-demographic and psychometric. Multiple logistic regression has been performed.

Results: Among 104 participants, severe burnout prevailed at $1.9 \%$ (95\% Cl: $0.2-6.8 \%)$ and burnout symptoms at $34.6 \%$ (95\% Cl: $25,6-44.6 \%)$. The associated factors with burnout symptoms: age (OR=0.86, $p=0.004)$, clinical activity in a university hospital center $(\mathrm{OR}=5.19, p=0.006)$, the easy access to the hospital $(\mathrm{OR}=0.59$, $p=0.012)$, number of elderly dependents living with the practitioner $(\mathrm{OR}=0.54, p=0.012)$, place of residence (same borough where the hospital is located: $O R=4.09, p=0.039$ ) and to be favorable to traditional medicine $(\mathrm{OR}=1.82, p=0.087)$. Nagelkerke's R-squared:53.1\%.

Conclusion: In Gabon, middle-income country, almost one practitioner in two has burnout symptoms. The young age, the university hospital center, the difficulty to access to hospital and to live in the borough where the hospital is located increase the probability of burnout symptoms. These results must put question to relevant authorities regarding health and medical education, to set up: a public transport for practitioners, an optimal primary health care system, a regulation of medical tasks in hospitals, a training in clinical supervision.
\end{abstract}

Keywords: Burnout, Factors, Gabon, Medical setting, Prevalence

\footnotetext{
* Correspondence: jrmackanga@gmail.com

'Center for Training and Research in Pedagogy of Health Sciences - Faculty

of Medicine, Strasbourg, 4 rue Kirschlager, F-67085 Strasbourg, France

${ }^{2}$ Department of Internal Medicine and Medical Specialties, University of

Health Sciences, Libreville, post box 4009, Libreville, Gabon

Full list of author information is available at the end of the article
}

(c) The Author(s). 2020 Open Access This article is licensed under a Creative Commons Attribution 4.0 International License, which permits use, sharing, adaptation, distribution and reproduction in any medium or format, as long as you give appropriate credit to the original author(s) and the source, provide a link to the Creative Commons licence, and indicate if changes were made. The images or other third party material in this article are included in the article's Creative Commons licence, unless indicated otherwise in a credit line to the material. If material is not included in the article's Creative Commons licence and your intended use is not permitted by statutory regulation or exceeds the permitted use, you will need to obtain permission directly from the copyright holder. To view a copy of this licence, visit http://creativecommons.org/licenses/by/4.0/ The Creative Commons Public Domain Dedication waiver (http://creativecommons.org/publicdomain/zero/1.0/) applies to the data made available in this article, unless otherwise stated in a credit line to the data. 


\section{Background}

The hospital is an environment where medical practice and medical training take place simultaneously. In health systems, the well-being of hospital practitioners is essential for good quality of care [1], and to achieve public health objectives [2]. Thus, a discomfort in hospital environment have a negative effect on the quality of care and medical education. Among the uncomfortable phenomena affecting hospital practitioners as physicians or medical students, burn-out is widely cited. Several definitions of burnout are described in the literature, but the description by Maslach and Jackson is the most used, defining burnout by three components or symptoms: emotional exhaustion, depersonalization and the reduction of personal accomplishment [3]. Burnout is quite studied in the social and medical context of developed countries [4], and this has allowed many socio-legal advances in favor of workers. Moreover, in line with these advances, recently in May 2019, the World Medical Association (WMA) welcomed the decision of the World Health Assembly to classify burnout syndrome as having an impact on health status and to incorporate it into the new version of the International Classification of Diseases of the World Health Organization (WHO) [5]. The WMA, through the voice of its president, urged that this decision of the WHO lead very soon to the adoption of a new approach, which will take into account multiple factors, including the working conditions of doctors across the world. However, in low- and middle-income countries that are characterized by modest quality of health care, medium medical training level and poor hospital conditions, burnout is still insufficiently studied.

Thus, the aim of the study was to determine in medical doctors and doctoral students, in the medical context of a middle-income sub-Saharan African country, the burnout level and the associated factors, in order to hypothesize potential etiological factors of burnout. This would guide research about cause and effect relationship in order to define specific actions, which could improve: the well-being of practitioners, the quality of care, and the medical training in these precarious conditions.

\section{Methods}

\section{Study design}

According to the aim of our study, a prospective crosssectional survey was conducted.

\section{Inclusion criteria and study settings}

The study concerned consenting medical practitioners, regardless of age or gender. These included medical doctors and doctoral medical students working part-time in clinical practice in Gabon at the moment of the study. Gabon is a sub-Saharan African middle-income country. It is populated by about 1.8 million inhabitants with about 3 to 4 physicians per 10,000 inhabitants [6], or approximately a total between 540 to 720 physicians. But these physicians are unequally distributed on the national territory [7].

\section{Sample size}

We determined the minimum sample size required for our survey based on an acceptable margin error of 5\%, a confidence level of $95 \%$ and an expected prevalence of severe burnout of approximately $7 \%$, average prevalence reported in the literature [8]. Thus, by applying the formula $n=\mathrm{z}^{2} \mathrm{x} \mathrm{p}(1-\mathrm{p}) / \mathrm{m}^{2}$ [9] ( $\mathrm{z}$ : for $95 \%=1.96$, $\mathrm{p}$ : assumed prevalence $=7 \%$ and $\mathrm{m}$ : acceptable margin error $=5 \%$ ), a minimum of 100 practitioners were required.

\section{Sampling and data collection}

The source population was physicians and medical doctoral students working in clinical practice in Gabon and registered on the professional Facebook forum of physicians in Gabon, and the WhatsApp forum of doctoral medical students in Gabon. The Facebook forum of physicians is a professional online forum (named "physicians of Gabon") where are registered 457 physicians on a total of 540 to 720 physicians in Gabon [6]. They represent around 63.5 to $84.6 \%$ of physicians in Gabon according to medical density and population size. All doctoral medical students are registered in a WhatsApp forum. In fact, in Gabon, there is only one medical school, and doctoral medical students were 153 in Gabon at the moment of study. For academic needs, all doctoral students are registered in a WhatsApp forum to facilitate communication in medical school of Gabon. These online forums bring together the majority of medical practitioners and all medical doctoral students in Gabon. Thus, we estimated that these forums had representative population of physicians and medical doctoral students for the study. We made a list on Excel sheet 2016 using Facebook addresses of the 457 physicians and WhatsApp addresses of the 153 doctoral medical students. The Facebook addresses are easily accessible to each physician registered in the professional Facebook forum, and the WhatsApp addresses were available from the student delegate. Probability sampling was performed using the ALEA function in Excel 2016. According to sample size expected, the first 100 (+30\%) addresses were selected and the link of anonymous questionnaire (with a cover text that succinctly explained the rationale of the study) has been sent to these online addresses. From time to time, reminders were necessary to mobilize the participants. The practitioners who answered the anonymous questionnaire according to their consent, were our study population (Fig. 1). Each anonymous questionnaire completed and submitted online was systematically collected on the database via google form. 


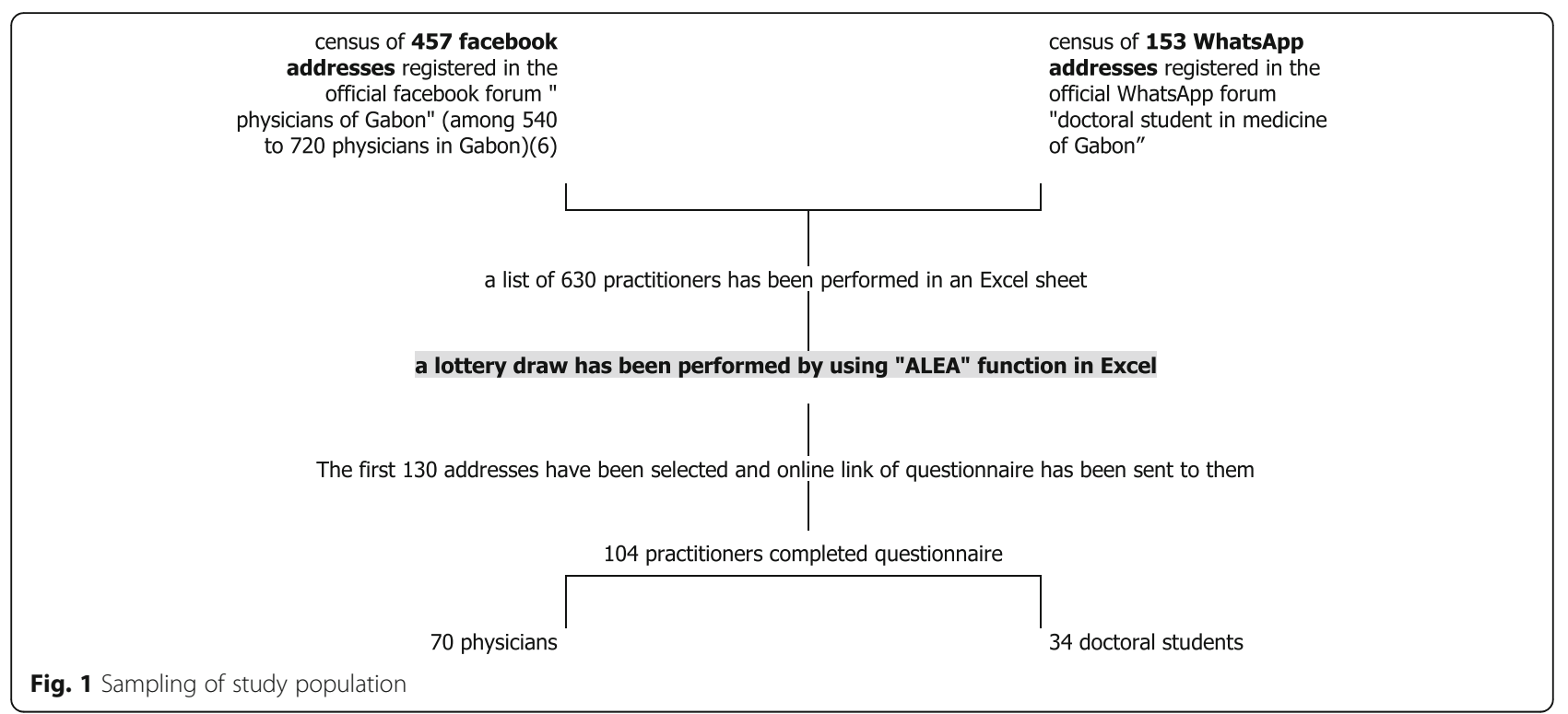

Data collection took place from November 1, 2018 to April 1, 2019. Data exported in Excel sheet to statistical analysis software.

\section{Variables operationalization}

- Practitioners feelings about burnout were collected by using the validated French version of Maslach Burnout Inventory - Human Services Survey for Medical Personnel (MBI-HSS (MP)), widely used [10]. Therefore, the following outcomes criteria have been defined:

- severe burnout defined by high level score in all 3 dimensions of the Maslach Burnout Inventory Scale: emotional exhaustion (EE) $\geq 27$ and depersonalization (DP) $\geq 10$ and personal achievement $(\mathrm{PA}) \leq 33$. Severe burnout was coded as a binary categorical variable (yes $=1$, no $=0$ ).

- burnout (or burnout symptom) defined by the existence of at least one high level score in one of the 3 dimensions of the Maslach Burnout Inventory Scale: EE score $\geq 27$ or DP score $\geq 10$ or AP score $\leq 33$. The burnout (the burnout symptom) was coded in binary categorical variable (yes $=1$, no $=0$ ).

- the psychometric data related to the perception of the practitioners were collected by a self-administered Likertscale questionnaire at 7 levels (proportionally to assertion worded) and treated as a numeric variable. These were the following parameters: a) the easy access to the hospital: in Gabon, public transport is poor and this suggests that the difficulty of access to the workplace could affect motivation, and therefore indirectly interacts to burnout. Thus, we have identified it as a potential factor to explore. $b$ ) the weekly frequency of the professional medical activity outside the public hospital: organization and equipment in private hospitals would make the working environment more satisfactory than in public hospitals. Or, working in the two hospitals could be overworked. Thus, we have identified it as a potential factor to explore. c) the frequency of activity in non-professional associations: taking part in extra-professional associative activities could be an environment that promotes humanization, or empathy skill, which is inversely correlated to burnout. Or, working simultaneously in non-professional associations could be overworked. Thus, we have selected it as a potential factor to explore. d) opinion favorable to traditional medicine: traditional medicine has a preponderant psychological orientation, supposing an understanding listening skill, which could interact with depersonalization feeling. Also, traditional medicine could be an alternative medicine where practitioners suffering of burnout symptoms would refer patients. Thus, we selected "to be favorable to traditional medicine" as potential factor to explore.

- demographic and socio-professional data: gender, marital status, hospital status (doctor versus doctoral medical student), hospital facility attended (university hospital center (UHC) versus other), extra-professional associative activity (yes versus no), means of transport (taxi versus personal car), place of residence relative to hospital (to live in same borough versus to live in different borough where the hospital is located) were coded as dichotomous categorical variables. Age, number of dependent children (living with the practitioner), number of elderly dependents (living with the practitioner), estimated average number of patients taken care of per day were coded as numerical variables.

\section{Statistical analysis \\ Descriptive study}

Categorical variables were summarized as a percentage expressed with a $95 \%$ confidence interval $(95 \% \mathrm{CI})$. The 
none normality of distributions of majority of numeric variables has been checked by One-Sample KolmogorovSmirnov test. Thus, numeric variables have been summarized by median with interquartile range (IQR).

\section{Analytical study}

- univariate analysis to evaluate the link between each variable and burnout symptoms was performed by Fisher's Chi-square test for categorical variables and the Mann-Whitney U-test for numeric variables. Variables associated to burnout symptoms with statistical significance less than 25\% $(p<0.25)$ were selected for the multivariate analysis. In view of the exploratory nature of our study which tested original factors, we chose $25 \%$ to reduce the risk of excluding possible factors masked by confounding factors [11]. Age, sex and place of residence relative to hospital (same or different borough from that of the hospital) were considered as forced variables for multivariate analysis.

- multivariate analysis was performed by binary multiple logistic regression using backward stepwise method (with Wald's statistic). The adjusted odd ratio (aOR) was the estimator of the association between the burnout symptoms event and potential factor. Backward stepwise method generated a final model of probable predictive factors of prevalent burnout symptoms. The thresholds for the probability of entering and removing factor in the model were set at 5 and $10 \%$ respectively. The quality of the final model of potential predictor factors was evaluated by the Nagelkerke's R-squared and the Hosmer-Lemeshow test. The French version of the SPSS 21 software (Statistical Package for the Social Sciences) was used.

\section{Results}

\section{Characteristics of the study population}

One hundred and four (104) medical practitioners completed the questionnaire. Majority groups were: female gender (sex ratio male $(\mathrm{M}) /$ female $(\mathrm{F})=0.52(95 \% \mathrm{CI}$ : 0.35-0.79), doctors (versus doctoral students) $67.3 \%$ (95\% CI 57.4-76.2\%), performing extra-professional associative activity $75.0 \%$ (95\% CI: 65.6-83.0\%) (Table 1).

\section{Burnout prevalence}

The prevalence of severe burnout was at $1.9 \%$ (95\% CI $0.2-6.8 \%)$. The burnout symptoms prevalence was at 34.6\% (95\% CI: $25.6-44.6 \%$ ): ie $\mathrm{EE} \geq 27: 17.3 \%$ (95\% CI: 10.6-26.0\%), DP $\geq 10: 25.0 \%$ (95\% CI: $17.0-34.5 \%$ ) and PA $\leq 33: 7.7 \%$ (95\% CI: 3.4-14.6\%) (Table 2).

\section{Associated factors to burnout symptoms}

Associated factors of burnout symptoms in univariate analysis: younger age $(p<0.0001)$, low number of dependent children $(p=0.044)$, low score regarding "easy access to the hospital" $(p=0.012)$, low score regarding "medical activity outside public hospital" $(p<0.0001)$, single $(\mathrm{OR}=2.6195 \% \mathrm{CI}$ : $1.14-6.00)$; medical student status $(\mathrm{OR}=3.2595 \% \mathrm{CI}: 1.37-7.69)$ and activity in University Hospital Center (UHC) OR $=3.50$ 95\% CI: 1.40-8.77 (Tables 3 and 4).

\section{Model of predictors of burnout symptoms (multivariate analysis)}

After logistic regression and adjusted, the following factors were retained in the predictive model: age in years $(\mathrm{aOR}=0.8695 \% \mathrm{CI}: 0.78-0.96 ; 0.004)$, activity in $\mathrm{UHC}(\mathrm{aOR}=5.1995 \% \mathrm{CI}: 1.61-16.75, p=0.006)$, score regarding " easy access to the hospital" (aOR $=0.5995 \%$ CI: $0.40-0.89, p=0.012$ ), the number of elderly dependents living with the practitioner $(\mathrm{aOR}=0.5495 \% \mathrm{CI}$ : $0.33-0.88, p=0.012$ ), to live in different borough (versus same borough) where the hospital is located $(\mathrm{aOR}=0.24$ 95\% CI: $0.06-0.93, p=0.039)$ and the favorable opinion score for traditional medicine ( $\mathrm{aOR}=1.82$ 95\% CI: 0.92 3.61, $p=0.087)$. The statistics of Hosmer-Lemeshow $=$ 18.7\% and Nagelkerke's R-squared 53.1\% (Table 5).

\section{Discussion}

\section{Burnout prevalence}

The high prevalence of burnout symptoms reflects work-related suffering in addition to the very difficult working conditions initially described in public hospitals in Gabon [12]. Given the prevalence of burnout symptoms in our study, it can be said that in the Gabonese medical settings, nearly half of all medical care situations are at risk of an unsatisfactory clinical outcome. Indeed, it is established that the existence of burnout symptoms is associated with an unfavorable clinical outcome for patients as opposed to an empathy that has an opposite effect [13-15]. Moreover, the data of our study show that the most prevalent symptom of burnout in Gabon's medical community is depersonalization (DP), and it is well established that this dimension of burnout means a low level of empathy [14]. This observation contributes more to explain the feeling of discomfort in the caregiver-patient relationship often reported by patients attending public hospitals [12] and forebodes the poor professional temperament in public hospitals [15]. However, the prevalence of burnout symptoms in Gabon's medical community is close to the values reported in the French, American (United States of America) and Asian medical settings $[8,14,16-18]$.

\section{Factors associated with burnout symptoms in Gabonese medical settings}

Young age is strongly associated with burnout symptom in Gabonese medical settings. With each increase of 1 year of age, the probability of having a burnout symptom 
Table 1 Characteristics of the study population ( $N=104$ (100\%)

\begin{tabular}{|c|c|c|c|c|}
\hline Age (year) & Mean, IQR & & 35.0 & $30.3-40.0$ \\
\hline \multicolumn{5}{|l|}{ Gender } \\
\hline female & n, \%, Cl 95\%. & 68 & $65.4 \%$ & $55.4-74.5 \%$ \\
\hline male & n, \%, Cl 95\%. & 36 & $34.6 \%$ & $25.6-44.6 \%$ \\
\hline \multicolumn{5}{|l|}{ Matrimonial status } \\
\hline single & n, \%, Cl 95\%. & 42 & $40.4 \%$ & $30.9-50.5 \%$ \\
\hline living maritally & n, \%, Cl 95\%. & 62 & $59.6 \%$ & $49.5-69.1 \%$ \\
\hline \multicolumn{5}{|l|}{ Place of residence and hospital } \\
\hline different borough & n, \%, Cl 95\%. & 56 & $53.9 \%$ & $43.8-63.7 \%$ \\
\hline same borough & $\mathrm{n}, \%, \mathrm{Cl} 95 \%$ & 48 & $46.2 \%$ & $36.3-56.2 \%$ \\
\hline \multicolumn{5}{|l|}{ Means of transport } \\
\hline taxi & $\mathrm{n}, \%, \mathrm{Cl} 95 \%$ & 52 & $50.0 \%$ & $40.0-60.0 \%$ \\
\hline personal car & $\mathrm{n}, \%, \mathrm{Cl} 95 \%$ & 52 & $50.0 \%$ & $40.0-60.0 \%$ \\
\hline Easy access to the hospital (self-assessment / scale from 0 to 7) & Median, IQR & & 4.0 & $3.0-5.0$ \\
\hline \multicolumn{5}{|l|}{ Hospital } \\
\hline Other & $n, \%, C l 95 \%$ & 42 & $40.4 \%$ & $30.9-50.5 \%$ \\
\hline University Hospital Center (UHC) & n, \%, Cl 95\%. & 62 & $59.6 \%$ & $49.5-69.1 \%$ \\
\hline \multicolumn{5}{|l|}{ Hospital status } \\
\hline doctoral student in medicine & n, \%, Cl 95\%. & 34 & $32.7 \%$ & $23.8-42.6 \%$ \\
\hline Doctor (physician) & $\mathrm{n}, \%, \mathrm{Cl} 95 \%$ & 70 & $67.3 \%$ & $57.4-76.2 \%$ \\
\hline \multicolumn{5}{|l|}{ Extra-professional associative activity } \\
\hline yes & $n, \%, C l 95 \%$ & 78 & $75.0 \%$ & $65.6-83.0 \%$ \\
\hline no & $n, \%, C l 95 \%$ & 26 & $25.0 \%$ & $17.0-34.5 \%$ \\
\hline Estimated number of patients supported per day & Median, IQR & & 10.0 & $10.0-17.3$ \\
\hline Number of elderly dependents living with the practitioner at home & Median, IQR & & 0.0 & $0.0-1.0$ \\
\hline Number of dependent children living with practitioner at home & Median, IQR & & 2.0 & $1.0-3.0$ \\
\hline $\begin{array}{l}\text { Attendance of extra-professional associations (self-assessment / } \\
\text { scale from } 0 \text { to } 7 \text { ) }\end{array}$ & Median, IQR & & 2.0 & $1.0-4.0$ \\
\hline $\begin{array}{l}\text { Frequency of medical activity outside public hospital per week } \\
\text { (self-assessment / scale from } 0 \text { to } 7 \text { ) }\end{array}$ & Median, IQR & & 2.0 & $1.0-3.8$ \\
\hline $\begin{array}{l}\text { To be favorable to traditional medicine (self-assessment / scale from } \\
0 \text { to } 7 \text { ) }\end{array}$ & Median, IQR & & 1.0 & $1.0-2.0$ \\
\hline Emotional Exhaustion (from 0 to 54) & Median, IQR & & 18.0 & $10.0-26.8$ \\
\hline Depersonalization (from 0 to 30) & Median, IQR & & 8.0 & $3.0-11.8$ \\
\hline Personal Achievement (from 0 to 48) & Median, IQR & & 40.5 & $36.0-42.8$ \\
\hline
\end{tabular}

decreases by $14 \%$. This result could be explained by a difficult phase of professional acculturation. A period where the young practitioner adapts to the work environment. Also, the young practitioner is often victim of the phenomenon of sliding tasks. Indeed, it is not uncommon to note the absence of a transparent regulation on the delegation of administrative or medical tasks entrusted to young practitioners or medical students. And, we can also evoke the probably overly directive relationship between the supervisor practitioner and the young supervised practitioner, while this relationship should be more collaborative and more cooperative. It is not uncommon for medical students to be treated more prominently as poorly listened employees and this, at the expense of their learner status. Indeed, medical student status as resident is also widely recognized as a factor associated with burnout symptoms in most studies [8].

The low score regarding "easy access to the hospital" is strongly associated with burnout symptoms. An improvement of one point on the Likert scale from 0 to 7 , decreases the probability of burnout symptoms by $40 \%$. This result could be explained by difficulties in accessing the hospital due to the lack of public transport, the poor condition of urban roads, which enclaves large urban 
Table 2 Prevalence of burnout in Gabonese medical settings. (Total $N=104$ )

\begin{tabular}{|c|c|c|c|c|}
\hline & $\mathrm{n}$ & $\%$ & $\mathrm{Cl} 95 \%$ & \\
\hline \multicolumn{5}{|l|}{ Burnout symptom (Emotional Exhaustion: EE) } \\
\hline High emotional exhaustion & 18 & $17.3 \%$ & $10.6 \%$ & $26.0 \%$ \\
\hline Moderate emotional exhaustion & 38 & $36.5 \%$ & $27.3 \%$ & $46.6 \%$ \\
\hline Low emotional exhaustion & 48 & $46.2 \%$ & $36.3 \%$ & $56.2 \%$ \\
\hline \multicolumn{5}{|l|}{ Burnout symptom (Depersonalization: DP) } \\
\hline High depersonalization & 26 & $25.0 \%$ & $17.0 \%$ & $34.5 \%$ \\
\hline Moderate depersonalization & 34 & $32.7 \%$ & $23.8 \%$ & $42.6 \%$ \\
\hline Low depersonalization & 44 & $42.3 \%$ & $32.7 \%$ & $52.4 \%$ \\
\hline \multicolumn{5}{|l|}{ Burnout symptom (Personal Accomplishment: PA) } \\
\hline Low Personal accomplishment & 8 & $7.7 \%$ & $3.4 \%$ & $14.6 \%$ \\
\hline Moderate Personal accomplishment & 40 & $38.4 \%$ & $29.1 \%$ & $48.5 \%$ \\
\hline High Personal accomplishment & 56 & $53.9 \%$ & $43.8 \%$ & $63.7 \%$ \\
\hline Burnout symptoms: $\mathrm{EE} \geq 27$ or $\mathrm{DP} \geq 10$ or $\mathrm{PA} \leq 33$ & 36 & $34.6 \%$ & $25.6 \%$ & $44.6 \%$ \\
\hline Severe burnout: $E E \geq 27$ and $D P \geq 10$ and $P A \leq 33$ & 2 & $1.9 \%$ & $0.2 \%$ & $6.8 \%$ \\
\hline
\end{tabular}

areas [19]. The urban enclaved areas are sources of prehospital demotivation. This demotivation contaminates the feeling at work and expose to burnout. These pre-hospital demotivation factors, can also explain the low practitioners performance [15]. Also, as our results show that young age is associated to burnout symptoms, it is more probable that students and young physicians who have modest income face more transport difficulties to get to hospital.

Working in the University Hospital Center (UHC) multiplies by 5 the probability of burnout symptoms. This could be explained by the frequent lack of care materials in UHC where the largest number of patients converge. This situation forces practitioners to devote a large part of their activity to solving social problems than medical problems. This context lowers the feeling of personal accomplishment, increases emotional exhaustion, and promotes depersonalization as a defense mechanism against the psychic pain of being unable to effectively solve patients' problems [20].

Living in the borough where the hospital is established is paradoxically associated with burnout. This result questions about inconveniences to be availability due to the proximity to workplace. This exposes the young practitioner to work overtime and be solicited during holidays. Also, living near the hospital can mean a modest economic conditions (students and young doctors), that motivate young practitioner for doing medical activity additionally and exposes them to burnout. The evaluation of the geographical distribution of the residences of the practitioners in relation to the hospitals according to the socio-economic level will need to be explored.

For each dependent elderly person living with the practitioner, the probability of having burnout symptoms decreases by $46 \%$. This suggest that a practitioner caring

Table 3 Link between numeric variables and burnout symptoms in Gabonese medical settings (bivariate analysis)

\begin{tabular}{|c|c|c|c|c|c|}
\hline \multirow[t]{3}{*}{ analyzed factors } & \multicolumn{4}{|c|}{ Burnout symptoms } & \multirow[t]{3}{*}{$\mathrm{p}$} \\
\hline & \multicolumn{2}{|c|}{ Yes $(N=36)$} & \multicolumn{2}{|c|}{ No $(N=68)$} & \\
\hline & Median & IQR & Median & IQR & \\
\hline Age (year) & 30 & $29-34$ & 38.5 & $32-41$ & $<0.0001$ \\
\hline Number of elderly dependents living with the practitioner at home & 0 & $0-0$ & 0 & $0-1$ & 0.203 \\
\hline Number of dependent children living with practitioner at home & 1.5 & $1-2$ & 2 & $1-3$ & 0.044 \\
\hline Estimated number of patients supported per day & 15 & $10-20$ & 10 & $10-15$ & 0.188 \\
\hline Easy access to the hospital (scale 0 to 7 ) & 3 & $1-5$ & 4 & $4-5$ & 0.012 \\
\hline Attendance of extra-professional associations (scale from 0 to 7 ) & 2 & $1-4$ & 2 & $1-4$ & 0.281 \\
\hline $\begin{array}{l}\text { Frequency of medical activity outside public hospital per week } \\
\text { (scale } 0 \text { to } 7 \text { ) }\end{array}$ & 1 & $1-2$ & 2 & $1-4$ & $<0.0001$ \\
\hline To be favorable to traditional medicine (scale 0 to 7 ) & 1.5 & $1-2$ & 1 & $1-2$ & 0.142 \\
\hline
\end{tabular}


Table 4 Link between categorical variables and burnout symptoms in Gabonese medical settings (bivariate analysis)

\begin{tabular}{|c|c|c|c|c|c|c|c|c|}
\hline \multirow[t]{2}{*}{ Variables } & \multirow[t]{2}{*}{ modality } & \multicolumn{2}{|c|}{ Burnout symptoms } & \multirow{2}{*}{$\begin{array}{l}\text { Total }= \\
104\end{array}$} & \multirow[t]{2}{*}{ OR } & \multirow[t]{2}{*}{ Cl 95\% } & & \multirow[t]{2}{*}{$p$} \\
\hline & & Yes (=36) & No $(=68)$ & & & & & \\
\hline \multirow[t]{2}{*}{ Gender } & female & 24 & 44 & 68 & 1.09 & 0.47 & 2.56 & 1 \\
\hline & male & 12 & 24 & 36 & reference & 1 & & \\
\hline \multirow[t]{2}{*}{ Matrimonial status } & single & 20 & 22 & 42 & 2.61 & 1.14 & 600 & 0.035 \\
\hline & living maritally & 16 & 46 & 62 & reference & 1 & & \\
\hline \multirow[t]{2}{*}{ Means of transport } & taxi & 22 & 30 & 52 & 1.99 & 0.87 & 4.54 & 0.149 \\
\hline & Personal car & 14 & 38 & 52 & reference & 1 & & \\
\hline \multirow[t]{2}{*}{ Hospital } & $\mathrm{UHC}$ & 28 & 34 & 62 & 3.5 & 1.4 & 8.77 & 0.007 \\
\hline & Other & 8 & 34 & 42 & reference & 1 & & \\
\hline \multirow[t]{2}{*}{ Extra-professional associative activity } & no & 12 & 14 & 26 & 1.93 & 0.78 & 4.79 & 0.163 \\
\hline & yes & 24 & 54 & 78 & reference & 1 & & \\
\hline \multirow[t]{2}{*}{ Hospital status } & Doctoral student & 18 & 16 & 34 & 3.25 & 1.37 & 7.69 & 0.008 \\
\hline & Doctor (physician) & 18 & 52 & 70 & reference & 1 & & \\
\hline \multirow[t]{2}{*}{ Place of residence and hospital } & different borough & 20 & 36 & 56 & 1.11 & 0.49 & 2.5 & 0.83 \\
\hline & Same borough & 16 & 32 & 48 & reference & 1 & & \\
\hline
\end{tabular}

for the elderly at home improves cognitive empathy. And empathy is inversely correlated with burnout.

Finally, the trend towards the association between the opinion score favorable to traditional medicine and the symptoms of burnout questions the interaction between burnout and the perception of certain social representations concerning norms, values and the beliefs of practitioners. Also, for practitioners, alternative medicine like traditional medicine could be a solution against burnout symptoms. This result needs qualitative study for more exploration, in order to understand how the caregiverpatient relationship operates in the acculturation of caregiver regarding his medical belief.

\section{Possible solutions to reduce the symptoms of burnout in} the Gabonese medical context

Hospital is the only place where young doctors and students acquire their medical skills. But, the well-being (in the learning environment) which is a determining factor for learning seems seriously impaired in Gabonese hospitals. In view of the above (university hospital center, low score regarding "easy access to the hospital" and young age as predictive factors of burnout symptoms), optimal medical learning and best health care are uncertain in this medical context. For this, some points must put question to relevant authorities regarding health and medical education, namely: 1-the construction of social housing near hospitals for resident or young practitioners, 2-set up a public transport system, 3-to promote a regulation of medical tasks in hospitals, 4- to promote optimal system of primary health care for helping UHC and 5- set up a training in clinical supervision for senior doctors. This could reduce the symptoms of burn-out in young practitioners, improve the well-being of practitioner in their medical practice and promote medical learning.

Table 5 Model of burnout symptoms predictors in Gabonese medical settings (multivariate analysis)

\begin{tabular}{|c|c|c|c|c|c|c|c|}
\hline \multirow[t]{2}{*}{ Factors } & \multirow[t]{2}{*}{ Coefficients } & \multirow[t]{2}{*}{$\mathrm{aOR}^{\mathrm{a}}$} & \multicolumn{2}{|c|}{$\mathrm{Cl} 95 \%$} & \multirow[t]{2}{*}{$\mathrm{p}$} & \multicolumn{2}{|l|}{ statistics of model } \\
\hline & & & & & & Nagelkerke's R-squared & Hosmer-Lemeshow's test \\
\hline University Hospital Center (versus other hospital) & 1.647 & 5.19 & 1.61 & 16.75 & 0.006 & 53.1 & 0.187 \\
\hline $\begin{array}{l}\text { To be favorable to traditional medicine } \\
\text { (self-assessment/scale } 0 \text { to } 7 \text { ) }\end{array}$ & 0.598 & 1.82 & 0.92 & 3.61 & 0.087 & & \\
\hline Age (year) & -0.15 & 0.86 & 0.78 & 0.96 & 0.004 & & \\
\hline Easy access to the hospital (scale from 0 to 7 ) & -0.521 & $0, .59$ & 0.40 & 0.89 & 0.012 & & \\
\hline $\begin{array}{l}\text { Number of elderly dependents living with the } \\
\text { practitioner at home }\end{array}$ & -0.616 & 0.54 & 0.33 & 0.88 & 0.012 & & \\
\hline $\begin{array}{l}\text { Place of residence: same (vs different) borough } \\
\text { from than of the hospital }\end{array}$ & -1.409 & 4.09 & 1.07 & 15.59 & 0.039 & & \\
\hline
\end{tabular}

adjusted odd ratio (aOR), with burnout symptoms as dependent variable 
The burnout topic is relevant, justifying our study which aimed to characterize the epidemiology of burnout in a precarious hospital environment in a sub-Saharan African medical setting. The survey design of the study and the statistical analysis are adequate to the research question. The statistical model of factors associated with burnout symptoms could explain burnout symptoms event at over 53\% according to Nagelkerke's R-squared adjusted (Table 5). This result indicates the potential etiological factors that will need to be explored in appropriate study design to verify a cause and effect relationship. Regarding to the physicians number (less than a thousand) in Gabon at the time of the study and the probability sampling performed, our study population is potentially representative $[6,7]$. However, the sampling has been performed by using facebook addresses obtained online through official facebook forum of physicians of Gabon and lacked stratification (two populations studied: doctoral students and doctors) could be a limit of our study. But, ratio between both populations in our study was in the expected range according to the source population, which minimize bias.

\section{Conclusion}

In medical settings of middle-income Gabon, almost one practitioner in two has burnout symptoms with a predominance of depersonalization. The young age, the University Hospital Center, to live in same borough where the hospital is located, the difficulty of access to the hospital and the lower number of elderly dependent adult living with the practitioner increase the probability of burnout symptoms. These results must put question to relevant authorities regarding health and medical education, namely: social housing of young practitioners, public transport, regulation of medical tasks, set up optimal system of primary health care for helping the university hospital center and promoting training in clinical supervision. The link between burnout symptoms and the opinion score favorable to traditional medicine suggest the need to understand how the doctor-patient relationship operates in the acculturation process of medical practitioners in Gabon.

\section{Abbreviations \\ CEl: Institutional Ethics Committee; CERMEL: Medical Research Center of Lambaréné; Cl: Confidence Interval; DP: Depersonalization; EE: Emotional Exhaustion emotional; F: Female; IQR: Inter Quartile Range; M: Male; OR: Odd ratio; p: $p$-value; PA: Personal accomplishment; SPSS: Statistical Package for the Social Sciences; UHC: University Hospital Center; vs: Versus; WHO: World Health Organization; WMA: World Medical Association}

\section{Acknowledgements}

We acknowledge the contribution of Medical Doctors Kombila Ulrich Davy, Kinga Armel, Mombo Ngoma Ghislain, Nzouto Patrick Dieudonné, Mbadinga Itu, Bikie Obiang Nadège Pelagie to the conduct of the study.

\section{Authors' contributions}

Study design, protocol development: JRM. Data collection: JRM, EGMM.
Statistical analysis: JRM, EGMM. Wrote manuscript: JRM. Contributed to writing of manuscript: JRM; EGMM, PP, JI, JBMK, JBB. All authors have read and approved the manuscript.

\section{Funding}

The study did not receive funding.

Availability of data and materials

The datasets used and/or analyzed during the current study are available from the corresponding author on reasonable request.

\section{Ethics approval and consent to participate}

Informed consent was mentioned in a few lines in the preamble of questionnaire. When the participant was consenting, he completed the questionnaire and submitted it online. The study was approved by the Institutional Ethics Committee of the Medical Research Center of Lambaréné (CERMEL) in Gabon. The Institutional Ethics Committee is a partner of the National Ethics Committee. The Institutional Ethics Committee is a member of the MARC network (Mapping African Research ethics review Capacity) and is registered with Registration Office for Human Research Protections with the numbers: IORG0007336 / IRB00008812. The protocol of the study has been registered with the number CEI-CERMEL 021/2018.

\section{Consent for publication}

Not applicable.

\section{Competing interests}

The authors declare that they have no competing interests.

\section{Author details}

${ }^{1}$ Center for Training and Research in Pedagogy of Health Sciences - Faculty of Medicine, Strasbourg, 4 rue Kirschlager, F-67085 Strasbourg, France. ${ }^{2}$ Department of Internal Medicine and Medical Specialties, University of Health Sciences, Libreville, post box 4009, Libreville, Gabon. ${ }^{3}$ Department of Internal Medicine, University of Nantes, 1 rue Gaston Veil - post box 53508, 44035 Nantes Cedex 1, France.

Received: 2 September 2019 Accepted: 11 August 2020

Published online: 10 September 2020

\section{References}

1. Dussault G, Dubois C-A. Human resources for health policies: a critical component in health policies. Hum Resour Health. 2003;1:1.

2. Dieleman M, Gerretsen B, van der Wilt GJ. Human resource management interventions to improve health workers' performance in low and middle income countries: a realist review. Health Res Policy Syst. 2009;7:7.

3. Maslach C, Jackson SE. The measurement of experienced burnout. J Organ Behav. 1981:2(2):99-113.

4. Soler JK, Yaman H, Esteva M, Dobbs F, Asenova RS, Katić M, et al. Burnout in European family doctors: the EGPRN study. Fam Pract. 2008;25(4):245-65.

5. WMA - The World Medical Association-L'Association médicale mondiale salue la décision sur le surmenage [Internet]. [cited 2019 Jul 15]. Available from: https://www.wma.net/fr/news-post/lassociation-medicale-mondialesalue-la-decision-sur-le-surmenage/.

6. Gabon - Médecins (par 1000 habitants) | Statistiques [Internet]. [cited 2019 Jul 15]. Available from: http://perspective.usherbrooke.ca/bilan/servlet/ BMTendanceStatPays?langue $=$ fr\&codePays $=$ GAB\&codeStat=SH.MED.PHYS. ZS\&codeStat2=SH.MED.PHYS.ZS.

7. Le personnel de santé au Gabon : une répartition inégale [Internet]. Gaboneco. [cited 2019 Jul 15]. Available from: http://www.gaboneco.com/ e-personnel-de-sante-au-gabon-une-repartition-inegale.html.

8. Kansoun Z, Boyer L, Hodgkinson M, Villes V, Lançon C, Fond G. Burnout in French physicians: a systematic review and meta-analysis. J Affect Disord. 2019;246:132-47.

9. Calcul de la taille optimale d'un échantillon [lnternet]. Analyse de données d'enquêtes de satisfaction. [cited 2019 Jul 16]. Available from: http://www. analyse-donnees.fr/calcul-de-la-taille-optimale-dun-echantillon/.

10. Dion G, Tessier R. Validation de la traduction de l'Inventaire d'épuisement professionnel de Maslach et Jackson. Can J Behav Sci. 1994;26(2):210-27.

11. El Sanharawi M, Naudet F. Comprendre la régression logistique. J Fr Ophtalmol. 2013;36(8):710-5. 
12. Ebang Ondo E. Perception de l'hôpital public et offre de soins de santé au Gabon : analyse des enjeux des interactions entre personnels et usagers du Centre Hospitalier de Libreville (CHL). Sous la Direction de Marc-Eric GRUENAIS, thèse d'Anthropologie Sociale et Ethnologie soutenue le 09/01/ 2012 à l'EHESS/Marseille. Bull Amades Anthropol Médicale Appliquée Au Dév À Santé [Internet]. 2012;(85) Available from: http://journals.openedition. org/amades/1398, [cited 2019 Jul 16].

13. Neumann M, Edelhäuser F, Tauschel D, Fischer MR, Wirtz M, Woopen C, et al. Empathy decline and its reasons: a systematic review of studies with medical students and residents. Acad Med. 2011;86(8):996-1009.

14. Lee PT, Loh J, Sng G, Tung J, Yeo KK. Empathy and burnout: a study on residents from a Singapore institution. Singap Med J. 2018;59(1):50-4.

15. CMLR B, Schroeder R, Rovi S, Boyd L. Relationships Between Medical Student Burnout, Empathy, and Professionalism Climate. Acad Med [Internet]. 2010:85(10) Available from: insights.ovid.com, [cited 2019 Jul 18]

16. Rothenberger D. Physician burnout and well-being: a systematic review and framework for action. Dis Colon Rectum. 2017:60(6):567-76.

17. Shenoi A, Kalyanaraman M, Pillai A, Raghava P, Day S. Burnout and psychological distress among pediatric critical care physicians in the United States*. Crit Care Med. 2018;46(1):116-22.

18. Li H, Zuo M, Gelb A, Zhang B, Zhao X, Yao D, et al. Chinese anesthesiologists have high burnout and low job satisfaction: a crosssectional survey. Anesth Analg. 2018;126(3):1004-12.

19. Etat du transport au Gabon - GABON PLURIEL [Internet]. 2010. Available from: http://nguemaagnandji.canalblog.com/archives/2010/06/02/18101959. html, [cited 2019 Jul 16].

20. Gleichgerrcht E, Decety J. Empathy in Clinical Practice: How Individual Dispositions, Gender, and Experience Moderate Empathic Concern, Burnout, and Emotional Distress in Physicians. PLoS One [Internet]. 2013;8(4) Available from: https://www.ncbi.nlm.nih.gov/pmc/articles/PMC3631218/, [cited 2019 Jul 18]

\section{Publisher's Note}

Springer Nature remains neutral with regard to jurisdictional claims in published maps and institutional affiliations.

Ready to submit your research? Choose BMC and benefit from:

- fast, convenient online submission

- thorough peer review by experienced researchers in your field

- rapid publication on acceptance

- support for research data, including large and complex data types

- gold Open Access which fosters wider collaboration and increased citations

- maximum visibility for your research: over $100 \mathrm{M}$ website views per year

At $\mathrm{BMC}$, research is always in progress.

Learn more biomedcentral.com/submissions 